\title{
Future Challenges for the Breeders Struggling the Climatic Changes
}

\author{
Badjakov I. ${ }^{1}$, Tsvetkov I. ${ }^{1}$, Dincheva I. ${ }^{1}$, Kondakova V. ${ }^{1}$, Atanassov A. ${ }^{2}$
}

\begin{abstract}
The Climate Change is one of the major problems in the entire world. The limiting influence of harmful factors as climate and other environmental changes, it will be crucial to breed new varieties for improved resistance to abiotic and biotic stresses. Climate Change can be tackled through plant breeding and better use of Plant Genetic Resources. Generally, plant breeding is the art and science of genetically improving plants for the benefit of humankind. It is important to mention potential contribution of organically managed systems to climate change mitigation is identified in the careful management of nutrients and, hence, the reduction of $\mathrm{N} 2 \mathrm{O}$ emissions from soils.

The application of biotechnological approaches, developing and implementation of new "omics" technologies and infrastructure construction on a high scientific level will help in building a strategy to overcome the damage of Climate Change.
\end{abstract}

Key words: Climate Change, plant breeding, organic agriculture, plant biotechnology, "OMICS” technologies.

\section{Plant breeding in the context of the climatic changes}

Nowadays one of the major problems widely recognized in the entire world is Climate Change. The Climate Change creates a serious threatening to push up the number of hungry people which is a result of negative impacts on food production. At the same time the growing global population will create an increased demand which will need to be produced on not much more land, using less water, fertilizer and pesticides (Fischer et al. 1994).

Looking at global issues we must be tackled correctly and in series with other global challenges of climate change as cleaner sustained energy and water security. Projections indicate that by 2030 the world will need to produce 50 percent more food, 50 percent more energy and 30 percent more fresh water and adapting to Climate Changes (Rosenzweig and Iglesias 1994). Some analysts of Climate Change explaining that if global temperatures do not increase more than $6^{\circ} \mathrm{C}$ over the next century, agricultural production can probably adapt to changes in mean global temperature using breeding, selection and management approaches.

The impact of Climate Change on production of various crops varies markedly depending mainly on the region, growing season, the crops and their temperature thresholds. To minimize the impacts of these climate and other environmental changes, it will be crucial to breed new varieties for improved resistance to abiotic and biotic stresses (Rosenzweig and Parry 1994). One of the major objectives for breeding research, 
in the context of climate change, is to understanding of the concept natural variation and how plants adapt to a range of natural and agricultural environments (Alonso-Blanco et al. 2009). Kliebenstein (2010) emphasizes the need for "more intricate, genomic, and broad phenotypic analyses of natural variation to address the fundamentals of quantitative genetics" in his update on the potential role of systems biology in uncovering the generation and maintenance of natural genetic variation.

Plant breeders need to increase their attention to breeding varieties that have greater tolerance to local abiotic stresses such as drought, flooding and extreme temperatures as well as continuing to breed for resistance to pests and diseases.

Water, food, health, land and environment which are the essential needs of life, are all threatened by climate change. There will be a tremendous decline in the crop yield impacting all other aspects of life. It is believed that "new climate era" will have its winner and loser species and unfortunately many of the valuable crops are likely to fall in the category of losers.

Climate Change can be tackled through plant breeding and better use of plant genetic resources. Generally, Plant breeding is the art and science of genetically improving plants for the benefit of humankind. With the discovery of genetics, plant breeding became a more reliable means to improve varieties (Rosenzweig et al. 1995). The applying a modern biotechnology as a tool used in plant breeding, the development of new adapted varieties has become a more precise and rapid process to guarantee an outstanding quality and performance.

\section{Organic agriculture and the climatic changes}

Organic farming avoids chemical dependency. Organic agriculture improves the fertility and structure of soils, using crop rotation, recycling of crop residues and applying organic manures and mulches to encourage the development of soil microorganisms. Organic farming methods also protect surface and ground water and help preserve biodiversity (Benkeblia, 2011).

Scialabba et al (2010) discussed the mitigation and adaptation potential of organic agricultural systems along three main features:

- $\quad$ farming system design

- $\quad$ crop land management and grassland

- $\quad$ livestock management

Potential contribution of organically managed systems to climate change mitigation is identified in the careful management of nutrients and, hence, the reduction of $\mathrm{N}_{2} \mathrm{O}$ emissions from soils (Diepeningen et al. 2006). Another high mitigation potential of organic agriculture lies in carbon sequestration in soils. In a first estimate, the emission reduction potential by abstention from mineral fertilizers is calculated to be about $20 \%$ and the compensation potential by carbon sequestration to be about $40-72 \%$ of the world's current annual agricultural greenhouse gas (GHG) emissions, but further research is needed to consolidate these numbers (Smith et al. 2008). On the adaptation side, organic agriculture systems have a strong potential for building resilient food systems in the face of uncertainties, through farm diversification and building soil fertility 
with organic matter (Blanco et al. 2008). Additionally, organic agriculture offers alternatives to energy-intensive production inputs such as synthetic fertilizers which are likely to be further limited for poor rural populations by rising energy prices (Pimentel, 2005). In developing countries, organic agricultural systems achieve equal or even higher yields, as compared to the current conventional practices, which translate into a potentially important option for food security and sustainable livelihoods for the rural poor in times of climate change (Badgley et al. 2007). Certified organic products cater for higher income options for farmers and, therefore, can serve as promoters for climatefriendly farming practices worldwide (Lobell et al. 2008).

\section{Major challenges for Plant Biotechnology}

Biotechnology is a broad discipline that studies the potential use of natural organisms and systems in agriculture, environment and many other fields. Plant tissue culture manipulation technologies are responsible for recent breakthroughs in plant biotechnology. The new biotechnological approaches to human health and management are making a significant contribution to attempts to improve the quality of life, food and nutrition, health care and the environment (Aravindaram et al. 2011). Research in plant biotechnology has previously focused primarily on agronomic characteristics to improve resistance or tolerance to biotic and abiotic stresses in particular crop plants.

Agricultural biotechnology is however not a solution or a means in itself and largely depends on the existence of effective breeding programmes. Thus, agricultural biotechnology can never replace conventional breeding, but can be a vitally important tool in supporting sustainable agricultural production and breeding systems to be highly adaptive and effective in serving local needs (Chikaire et al. 2012). To meet the challenges a broad interdisciplinary approach needs to be taken next to the scientific and technological prerequisites that have to be met. Multidisciplinary is not only needed to transfer knowledge generated with model plants into crops, or even highly environmentally specialized varieties, but also to stimulate public acceptance and thus decreasing regulatory restraints. This will lead to address new challenges for Plant Biotechnology (Kossmann, 2012):

- Increase crop productivity especially in adverse environments

- Management of herbicide tolerance

- Management of resistance to pests

- Management of resistance to diseases

- Improvement of genetic engineering technologies to enhance public perception

- Improvement of harvest index

- Improvement of nutrient cycling in agricultural ecosystems

Finally, there is the ultimate challenge to genetically tailor plant products to optimally suit them as sources of food, feed, fuel, materials, and pharmaceuticals. The ultimate challenge is to understand and influence metabolism without compromising environment, crop productivity, unless high- value compounds such as pharmaceuticals are produced in other plant systems than crops, e.g., in plant cell or tissue cultures (Kossmann, 2012). 


\section{Next 'OMICS' development}

In the beginning of 21 st century the modern technologies brought plant science to new horizons. Since the beginning of the new millennium, "omics" sciences have been rapidly developed and optimized, generating a large amount of data that could be used for crop improvement. The main technologies- genomics, proteomics and metabolomics - can give a close-up of the pathways that link genotype to phenotype. These three main omics technologies involve quantification and characterization of genome, proteome and metabolome, respectively, with extremely rapid, miniaturized and automated methods (Bino, 2004). These technologies are aimed at unraveling the overall expression of genes, proteins and metabolites in a functionally relevant context, and provide ideas into the molecular basis of various fundamental processes involved in growth and development of plants and their environment (Fiehn, 2000). The omics technologies enable a direct and unbiased monitoring of the factors affecting crop growth and yield formation, and provide the data that can be directly utilized to investigate the complex interplay between the plant, its metabolism, and also the stress represented by the environment or the biological threats by insects, fungi or other pathogens (Dixon, 2006). To face the problems generated by these stresses, metabolomics are one of new strategies developed, and a number of targeted metabolome analyses were carried out to assess the involvement of subsets of metabolities in various stresses (Urano et al. 2010).

These technologies also help for investigation of the biology behind agronomic traits at the physiological, biochemical and molecular levels, and permit the clearing of molecular schemes of the crop plants, for improved crop production. Indeed, the various-'omics' have become a staple of Plant Physiology research (Campbell, 2006). The mention above disciplines applied in the context of nutrition and health have the potential to deliver biomarkers for health and comfort, reveal early indicators for disease disposition and discover bioactive, beneficial food components.

"Omics" technologies are relatively new biomarker discovery tools that can be applied to study large sets of biological molecules. The numbers of these technologies is constantly expanding. The field of technology ranges from genomics, proteomics and metabolomics (Vlaanderen et al. 2010).

For efficient gene function analysis, researchers can chose from a multitude of different methods from plant functional genomics. During recent years it has become increasingly clear, however, that each method has its inherent limitations and none of them alone suffice to assign a function to a gene of interest.

It's clear that metabolomics has quickly gained its place in modern plant science in both a fundamental and applied context. Using a metabolomics approach to identify key loci will play a significant role in helping to deconstruct complex metabolic interactions and provide the knowledge to design better crops to feed the world (Baxter and Borevitz, 2006). Metabolomics describes recent high-throughput approaches in the field of metabolic genomics that aim to identify gene function on the basis of analyzing the metabolome, the full complement of metabolites of an organism (Badjakov et al. 2011). In contrast to the genome, the proteome is highly variable over time, between cell types and will change in response to changes in its environment (Flisern et al. 2007). 
The 'OMICS' technologies - genomics and metabolomics are the basis for the rapid development of the new interdisciplinary field - nutrigenomics.

The increase in productivity has been powered by changes in the genetic potential of crops and relevant management practices.

\section{Conclusions}

$\checkmark \quad$ Climate change poses challenges to the agricultural sector -reducing GHG emissions and adapting to climate change.

$\checkmark \quad$ Innovation along the whole food chain, involving all relevant stakeholders, is critical.

The farmer must be in the middle - especially the small-scale farmer participatory processes are critical.

$\checkmark \quad$ The effect of climate on pests may add to the effect of other factors such as the overuse of pesticides and the loss of biodiversity due to pests and disease outbreaks.

$\checkmark \quad$ Science and technology is critical - the risks and benefits of all technologies must be evaluated.

Acknowledgment: Acknowledgments: We acknowledge the support of the EEA Scholarship Programme BG09 under the European Economic Area Financial Mechanism, project № D03-92/27.05.2015.

\section{References}

Aravindaram,K., and Ning-Sun Yang (2011). Applications of Agricultural and Medicinal Biotechnology in Functional Foods in Sustainable Agriculture and New Biotechnologies (pp. 257-270 ): CRC Press.

Alonso-Blanco, C., Aarts, M. G. M., Bentsink, L., Keurentjes, J. J. B., Reymond, M., Vreugdenhil, D., \& Koornneef, M. (2009). What Has Natural Variation Taught Us about Plant Development, Physiology, and Adaptation? The Plant Cell, 21(7), 1877-1896.

Badgley, C., Moghtader, J., Quintero, E., Zakem, E., Chappell, M. J., Aviles-Vazquez, K., et al. (2007). Organic agriculture and the global food supply. Renewable agriculture and food systems, 22, 86-108.

Badjakov, I., Kondakova, V., and Atanassov, A. (2012). Metabolomics: Current View on Fruit Quality in Relation to Human Health: Sustainable Agriculture and New Technologies. Boca Raton: CRC Press, 303-319.

Baxter, I. R., and Borevitz, J. O. (2006). Mapping a plant's chemical vocabulary. Nat Genet, 38(7), 737-738.

Benkeblia, N. (2011). Mining Omic Technologies and Their Application to Sustainable Agriculture and Food Production Systems. In Sustainable Agriculture and New Biotechnologies (pp. 117-148): CRC Press.

Bino, R. J., Hall, R. D., Fiehn, O., Kopka, J., Saito, K., Draper, J., et al. (2004). Potential of metabolomics as a functional genomics tool. Trends Plant Sci, 9(9), 418-425.

Blanco-Canqui, H., and Lal, R. (2008). Restoration of Eroded and Degraded Soils Principles of Soil Conservation and Management. Dordrecht: Springer Netherlands, (pp. 399-423).

Campbell, AM and Heyer LJ (2006). Discovering Genomics, Proteomics, and Bioinformatics. CSHL Press (BenjaminCummings), New York.

Chikaire, J., Nnadi, F., Ejiogu-Okereke, N., and Echetama, J. (2012) Participatory Technology Development: Current Approach to Sustainable Agricultural Biotechnology Development. Continental J. Sustainable Development, 3: 1-18. 
van Diepeningen, A. D., de Vos, O. J., Korthals, G. W., \& van Bruggen, A. H. C. (2006). Effects of organic versus conventional management on chemical and biological parameters in agricultural soils. Applied Soil Ecology, 31: 120-135.

Dixon, R. A., Gang, D. R., Charlton, A. J., Fiehn, O., Kuiper, H. A., Reynolds, T. L., et al. (2006). Applications of metabolomics in agriculture. J Agric Food Chem, 54: 8984-8994.

Fiehn, O., Kopka, J., Dörmann, P., Altmann, T., Trethewey, R. N., \& Willmitzer, L. (2000). Metabolite profiling for plant functional genomics. Nat Biotechnol, 18(11), 1157-1161.

Fliser, D., Novak, J., Thongboonkerd, V., Argilés, A., Jankowski, V., Girolami, M. A., et al. (2007). Advances in urinary proteome analysis and biomarker discovery. J Am Soc Nephrol, 18(4), 1057-1071.

Fischer, G., Frohberg, K., Parry, M. L., \& Rosenzweig, C. (1994). Climate change and world food supply, demand and trade. Global Environmental Change, 4(1), 7-23.

Kliebenstein, D. J. (2010). Systems biology uncovers the foundation of natural genetic diversity. Plant Physiol, 152(2), 480-486.

Kossmann, J. (2012). Grand challenges in plant biotechnology. Frontiers in plant science, (3) 61.

McMichael, A.J., Campbell- Lendrum, D.H., Corvalan, C.F., Ebi, K.L., Githeko, A.K., Scheraga, J.D., and Woodward, A. (2003). Climate Change and Human Health: Risks and Responses. Chapter 2.Geneva: World Health Organization.

Lobell, D. B., Burke, M. B., Tebaldi, C., Mastrandrea, M. D., Falcon, W. P., \& Naylor, R. L. (2008). Prioritizing Climate Change Adaptation Needs for Food Security in 2030. Science, 319(5863), 607610.

Pimentel, D., Hepperly, P., Hanson, J., Douds, D., and Seidel, R. (2005). Environmental, energetic and economic comparison of organic and conventional farming systems. Bioscience 55:573-582.

Rosenzweig, C., and Iglesias, A. (1994). Implications of climate change for international agriculture: Crop Modeling Study. US Environmental Protection Agency. EPA 230-B-94-003, Washington DC.

Rosenzweig, C., and Parry, M. L. (1994). Potential impact of climate change on world food supply. Nature, 367(6459), 133-138.

Rosenzweig, C., Allen, L.H., Harper, Jr., Hollinger, L.A., and Jones, J.W. (eds.). (1995) Climate Change and Agriculture: Analysis of Potential International Impacts. ASA Special Publication No. 59. American Society of Agronomy, Madison, WI. 382 p.

Scialabba, N., and Lindenlauf, M. (2010) Organic agriculture and climatic changes. Renewable Agriculture and Food Systems 25(2): 158-169.

Smith, P., Martino, D., Cai, Z., Gwary, D., Janzen, H., Kumar, P., et al. (2008). Greenhouse gas mitigation in agriculture. Philosophical Transactions of the Royal Society of London B: Biological Sciences, 363(1492): 789-813.

Urano, K., Kurihara, Y., Seki, M., \& Shinozaki, K. (2010). 'Omics' analyses of regulatory networks in plant abiotic stress responses. Curr Opin Plant Biol, 13(2), 132-138.

Vlaanderen, J., Moore, L. E., Smith, M. T., Lan, Q., Zhang, L., Skibola, C. F., et al. (2010). Application of OMICS technologies in occupational and environmental health research; current status and projections. Occup Environ Med, 67(2), 136-143. 